\title{
Direct Isomaltulose Synthesis From Beet Molasses by Immobilized Sucrose Isomerase
}

\section{OPEN ACCESS}

Edited by: Helen Treichel,

Universidade Federal da Fronteira Sul,

Brazil

Reviewed by:

Vesna Milorad Vučurović, University of Novi Sad, Serbia

Małgorzata Krzywonos, Wrocław University of Economics,

Poland

*Correspondence: Jian-Hua Hao haojh@ysfriac.cn Zai-Chao Ma mazc@sdu.edu.cn

Specialty section:

This article was submitted to Bioprocess Engineering,

a section of the journal Frontiers in Bioengineering and Biotechnology

Received: 06 April 2021 Accepted: 23 June 2021

Published: 16 July 2021

Citation:

Wang Q-Q, Yang $M$, Hao J-H and Ma Z-C (2021) Direct Isomaltulose Synthesis From Beet Molasses by Immobilized Sucrose Isomerase. Front. Bioeng. Biotechnol. 9:691547. doi: 10.3389/fbioe.2021.691547

\begin{abstract}
Qin-Qing Wang 1,2, Ming Yang ${ }^{3}$, Jian-Hua Hao ${ }^{4,5 *}$ and Zai-Chao Ma ${ }^{1 *}$
${ }^{1}$ National Glycoengineering Research Center, State Key Laboratory of Microbial Technology, Shandong University, Qingdao, China, ${ }^{2}$ School of Marine Sciences, Sun Yat-sen University, Guangzhou, China, ${ }^{3}$ Helmholtz International Lab for Anti-Infectives, Shandong University-Helmholtz Institute of Biotechnology, State Key Laboratory of Microbial Technology, Shandong University, Qingdao, China, ${ }^{4}$ Key Laboratory of Sustainable Development of Polar Fishery, Ministry of Agriculture and Rural Affairs, Yellow Sea Fisheries Research Institute, Chinese Academy of Fishery Sciences, Qingdao, China,

${ }^{5}$ Laboratory for Marine Drugs and Bioproducts, Qingdao National Laboratory for Marine Science and Technology, Qingdao, China
\end{abstract}

Isomaltulose is becoming a focus as a functional sweetener for sucrose substitutes; however, isomaltulose production using sucrose as the substrate is not economical. Low-cost feedstocks are needed for their production. In this study, beet molasses (BM) was introduced as the substrate to produce isomaltulose for the first time. Immobilized sucrose isomerase (Slase) was proved as the most efficient biocatalyst for isomaltulose synthesis from sulfuric acid $\left(\mathrm{H}_{2} \mathrm{SO}_{4}\right)$ pretreated $\mathrm{BM}$ followed by centrifugation for the removal of insoluble matters and reducing viscosity. The effect of different factors on isomaltulose production is investigated. The isomaltulose still achieved a high concentration of $446.4 \pm 5.5 \mathrm{~g} / \mathrm{L}$ (purity of $85.8 \%$ ) with a yield of $0.94 \pm 0.02 \mathrm{~g} / \mathrm{g}$ under the best conditions $(800 \mathrm{~g} / \mathrm{L}$ pretreated BM, $15 \mathrm{U}$ immobilized Slase/g dosage, $40^{\circ} \mathrm{C}, \mathrm{pH}$ of 5.5, and $10 \mathrm{~h}$ ) in the eighth batch. Immobilized Slase used in repeated batch reaction showed good reusability to convert pretreated BM into isomaltulose since the sucrose conversion rate remained $97.5 \%$ in the same batch and even above 94\% after 11 batches. Significant cost reduction of feedstock costs was also confirmed by economic analysis. The findings indicated that this two-step process to produce isomaltulose using low-cost BM and immobilized Slase is feasible. This process has the potential to be effective and promising for industrial production and application of isomaltulose as a functional sweetener for sucrose substitute.

Keywords: beet molasses, isomaltulose, sucrose isomerase, immobilization, economic analysis

\section{INTRODUCTION}

Molasses is a viscous by-product of sugar refineries with a sweet taste and color ranging from brown to dark-brown, which mainly includes cane molasses (CM), soy molasses (SM), and beet molasses (BM). The molasses is rich in sucrose and is also composed of a minimum amount of carbohydrates (like glucose) and other components (e.g., proteins, vitamins, and heavy metals) (Wang et al., 2019a; Palmonari et al., 2020). Particularly, large amounts of BM, annually, (more than 300,000 tons) were 
discharged in China in the past years, and only a little amount was used as grinding aid, feed, and carbon source (Gao et al., 2011; Yan et al., 2011), aggravating BM waste and causing serious environmental concerns. In other countries, BM has been utilized as sucrose-containing feedstock for microbes to produce value-added products, such as bioethanol (Razmovski and Vučurović, 2012; Vučurović et al., 2019), lipids (Taskin et al., 2016), hydrogen (Emrah et al., 2018), baker's yeast (Ferrari et al., 2001), and inulinase (Germe and Turhan, 2020). Therefore, BM is a very valuable raw material. Recently, BM has attracted increasing attention for different industrial applications worldwide, including China, due to its higher sucrose content (about 50\%) than those (about 30-50\%) of other molasses (Álvarez-Cao et al., 2019; Ozdal and Başaran Kurbanoglu, 2019; Wang et al., 2019a; Zheng et al., 2019; Palmonari et al., 2020; Zhan et al., 2020).

Sucrose is of importance as a widely used sweetener in the daily diet; however, high sucrose diet could trigger health problems, such as obesity, dental caries, type 2 diabetes, and Alzheimer's disease, due to the rapid increase in blood glucose and high sweet content of sucrose (Tian et al., 2019; Du et al., 2020; Yeh et al., 2020). Therefore, safe sweeteners with suitable sweetness were required for sucrose alternatives. Isomaltulose shows a similar appearance and taste to sucrose (Zhang et al., 2020) and has approximately 50\% sweetening power of sucrose (Shyam et al., 2018). In addition, isomaltulose has been authorized as "generally recognized as safe" by the United States Food and Drug Administration (Mu et al., 2014), sharing advantageous health benefits including lower glycemic index, lower calorie content, body-weight reduction, higher stability, more tooth-friendly, and promoting probiotics as well as prebiotics activities (Shyam et al., 2018; Lightowler et al., 2019; Wang et al., 2019a; Lee et al., 2020). Hence, isomaltulose is a promising functional sweetener and can be utilized as an available sucrose substitute.

As a structural isomer of sucrose, isomaltulose is a natural disaccharide consisting of glucose and fructose connected by $\alpha$-1,6-glycosidic bond. It can be converted from sucrose through isomerization catalyzed by sucrose isomerase (SIase), which is primarily derived from microbial processes and also produces small amounts of trehalulose, glucose, and fructose (Liu et al., 2020; Zhang et al., 2020). SIase-producing microbes for isomaltulose biosynthesis have been mainly found in bacteria including Pantoea dispersa (Wu and Birch, 2004), Enterobacter spp. (Park et al., 2010), Protaminobacter rubrum (de OlivaNeto and Menão, 2009), Serratia plymuthica (Duan et al., 2016), Klebsiella spp. (Li et al., 2003), and Erwinia spp. (Li et al., 2011). Recently, to improve isomaltulose production via a safe and efficient enzymatic method, various measures on heterologous expression of SIase gene, such as optimizing the promoter and/or signal peptide (Park et al., 2010; Zhang et al., 2018), site-directed mutagenesis for high thermostability (Duan et al., 2016), and displaying it on the cell surface of bacteria and fungi (Lee et al., 2011; Li et al., 2013, 2017; Wu et al., 2017; Zheng et al., 2019; Zhan et al., 2020), are explored. Among the targeted expression systems above, an ascomycetous yeast, Yarrowia lipolytica, seems to be the most attractive one based on relatively high isomaltulose yield $(0.96 \mathrm{~g} / \mathrm{g})$ production ( $\mathrm{Li}$ et al., 2017; Zhang et al., 2018). Noteworthily, sucrose substrate is indeed responsible for cell growth as a carbon source and isomerization of SIase during bioconversion processes, leading to the decrease of isomaltulose yield and unexpected products formation (Li et al., 2017; Zhang et al., 2018; Tian et al., 2019). The inner consumption of sucrose and non-target products formation are still inevitable, including using free or immobilized cells for isomaltulose production, suggesting that using free or immobilized SIase to produce isomaltulose directly will be expected to reduce the formation of non-target products (Li et al., 2003, 2011; Tian et al., 2019).

The cost of sucrose for isomaltulose production accounts for more than half of the total cost (Wang et al., 2019b). To reduce the cost of isomaltulose production for wide industrial applications, using cost-effective feedstocks as substrate apart from efforts in improving SIase expression is also needed. BM is a low-cost and readily available raw material, which has been employed as a carbon source for microbial growth; however, a strategy to use $\mathrm{BM}$ as a simple substrate for isomaltulose production has not been reported yet.

Several engineered $Y$. lipolytica strains with food grade can be used to produce isomaltulose from sucrose, CM, and SM (Zhang et al., 2018; Wang et al., 2019a,b). Pretreated SM was exactly used as a favorable substrate to produce isomaltulose by microbial fermentation (Wang et al., 2019b), and immobilized SIase could elevate the conversion rate of sucrose and isomaltulose concentration (Zhang et al., 2019). This study aims to explore the pretreatment and the effect of different factors on the potential of low-cost BM as the sole substrate for isomaltulose production using immobilized SIase. The final goal of this investigation is to reduce enzyme demand and explore the feasibility of this process for the industrial production of isomaltulose by economic analysis.

\section{MATERIALS AND METHODS}

\section{Strain and Media}

The yeast $Y$. lipolytica JD is a transformant carrying the strong promoter (TEFin) and SIase gene from $P$. dispersa UQ68J, which was cultivated in the medium containing glucose $(30 \mathrm{~g} / \mathrm{L})$ and corn steep powder $(20 \mathrm{~g} / \mathrm{L})$ with an initial $\mathrm{pH}$ of 6.0 for $72 \mathrm{~h}$ under the conditions of $30^{\circ} \mathrm{C}$ and $180 \mathrm{rpm}$ to achieve extracellular SIase (49.3 U/mL) (Zhang et al., 2019). The strain JD was used for SIase production in this study. Another strain, Y. lipolytica G82, expressing the $\alpha$-galactosidase gene was used to produce extracellular $\alpha$-galactosidase $(121.6 \mathrm{U} / \mathrm{mL})$ when cultivated in the GPPB medium [containing $30 \mathrm{~g} / \mathrm{L}$ glucose, $1.0 \mathrm{~g} / \mathrm{L}\left(\mathrm{NH}_{4}\right)_{2} \mathrm{SO}_{4}, 6.0 \mathrm{~g} / \mathrm{L}$ yeast extract, $2.0 \mathrm{~g} / \mathrm{L} \mathrm{KH}_{2} \mathrm{PO} 4,3.0 \mathrm{~g} / \mathrm{L}$ $\mathrm{K}_{2} \mathrm{HPO}_{4}$, and $0.1 \mathrm{~g} / \mathrm{L} \mathrm{MgSO}_{4} .7 \mathrm{H}_{2} \mathrm{O}, \mathrm{pH} 6.0$ ] at $30^{\circ} \mathrm{C}$ for 3 days (Wang et al., 2019b).

\section{Determination of Sugar Concentration of Molasses}

Raw CM was obtained from a sugar refinery in Guangxi. Raw $\mathrm{SM}$ was provided from a local soybean oil factory, and raw 
BM was supplied from Xinjiang. Different sugars contents of these raw molasses were detected by high-performance liquid chromatography (HPLC) using an Agilent 1200 system (Agilent Technologies, United States) and $\mathrm{NH}_{2}$ column (Thermo Fisher Scientific, United States). The carbohydrates (e.g., sucrose, glucose, fructose, stachyose, xylose, galactose, isomaltulose, and trehalulose) were all calculated according to peak areas and retention time.

\section{Pretreatment of BM}

Beet molasses was treated as the described method (Cheng et al., 2017). Briefly, BM was acidified to the $\mathrm{pH}$ of 3 by $3 \mathrm{M}$ sulfuric acid $\left(\mathrm{H}_{2} \mathrm{SO}_{4}\right)$ and boiled for $5 \mathrm{~min}$. The mixture would be centrifuged at $8,000 \mathrm{rpm}$ for $30 \mathrm{~min}$ after keeping it at $4^{\circ} \mathrm{C}$ for about $12 \mathrm{~h}$. $\mathrm{Ca}(\mathrm{OH})_{2}$ was added to the supernatant obtained to adjust $\mathrm{pH}$ to 6 . Then, it was centrifuged at the same condition to remove insoluble matters and evaporated to obtain the dry matter as 78.0\%. Then, the pretreated BM was diluted with distilled water to the targeted content. The clarified molasses solution was stored at $4^{\circ} \mathrm{C}$ until further use.

\section{SM Pretreated by $\alpha$-Galactosidase}

The pretreatment of SM was carried out by adding $\alpha$-galactosidase with the activity of $121.6 \mathrm{U} / \mathrm{mL}$ from the crude fermentation broth of G82 strain, which was cultivated at $45^{\circ} \mathrm{C}$ and $\mathrm{pH}$ of 4.5 for $4 \mathrm{~h}$, and the usage of $\alpha$-galactosidase was $15 \mathrm{U} / \mathrm{g}$ of SM as described by Wang et al. (2019b). For sugar content determination, the obtained hydrolysate was analyzed by HPLC.

\section{Isomaltulose Production Using Free and Immobilized Slase}

Isomaltulose production was conducted by free SIase and immobilized SIase from the crude fermentation broth of $Y$. lipolytica strain JD using sucrose as substrate, BM, and pretreated BM. Crude-free SIase was obtained by centrifugation $\left(10,000 \times g, 20 \mathrm{~min}, 4^{\circ} \mathrm{C}\right)$. In addition, SIase immobilization was carried out according to the previous study (Zhang et al., 2019). Briefly, polyvinyl alcohol (PVA, 10\%) and sodium alginate (1\%) were mixed with distilled water to obtain the final concentration of $1 \mathrm{~g} / 100 \mathrm{ml}$ and autoclaved at $115^{\circ} \mathrm{C}$ for $20 \mathrm{~min}$. Then, SIase solution $(40 \mathrm{U} / \mathrm{g})$ was dropped to the PVA-alginate mixture after cooling it to room temperature. The SIase-PVA-alginate suspension $(2 \mathrm{ml})$ was added through syringe needle dropwise into the crosslink boric acid solution ( $\mathrm{pH}$ 8.0) under continuous steering, and the beads of PVA-borate SIase were immersed in it for $2 \mathrm{~h}$ at $4^{\circ} \mathrm{C}$ to ensure sufficient gelation reaction. Subsequently, the beads were washed with distilled water to remove the excess borate ions from the surface. The enzyme recovery rate was defined as the ratio of immobilized SIase activity to total SIase activity. Free or immobilized SIase was added to $300 \mathrm{~g} / \mathrm{L}$ sucrose or $500 \mathrm{~g} / \mathrm{L} \mathrm{BM}$, with the SIase dosage of $15 \mathrm{U} / \mathrm{g}$ at $40^{\circ} \mathrm{C}$ and $\mathrm{pH} 6$ in the isomerization process. The sucrose concentrations in $500 \mathrm{~g} / \mathrm{L}$ raw BM and pretreated BM were $256 \mathrm{~g} / \mathrm{L}$ and $304.5 \mathrm{~g} / \mathrm{L}$, respectively, making the sucrose contents similar to $300 \mathrm{~g} / \mathrm{L}$. The produced isomaltulose content was also analyzed by using HPLC.

\section{Investigation of the Effect of Main Process Parameters on the Conversion of Pretreated BM to Isomaltulose}

The catalysis condition of immobilized SIase was determined for the best of isomaltulose production using one-way ANOVA. The reaction factors $\mathrm{pH}(5.5-7.5)$, pretreated $\mathrm{BM}$ of different concentrations (400-900 g/L), and SIase adding dosages (5-25 U/g) were implemented for isomaltulose production. Corresponding sucrose concentrations in pretreated $\mathrm{BM}$ were $243.6 \mathrm{~g} / \mathrm{L}, 304.5 \mathrm{~g} / \mathrm{L}, 365.4 \mathrm{~g} / \mathrm{L}, 426.3 \mathrm{~g} / \mathrm{L}, 487.2 \mathrm{~g} / \mathrm{L}$, and $548.1 \mathrm{~g} / \mathrm{L}$, respectively. The reusability of immobilized SIase was evaluated under the best conditions for 16 cycles based on the conversion rate of the substrate at $40^{\circ} \mathrm{C}$ and $\mathrm{pH}$ 6.0. When the optimal duration of $12 \mathrm{~h}$ of each cycle was finished, the beads were filtrated with a $1 \mu \mathrm{m}$ filter membrane and washed with distilled water, and then reused in the next cycle (Zhang et al., 2019). The contents of isomaltulose and others in the mixture in each cycle were determined by HPLC.

\section{Process Parameters}

Related parameters in this study were all calculated. Isomaltulose proportion (\%) was calculated with the content of produced isomaltulose divided by total sugars containing other produced sugars and residual sugars. Sucrose proportion (\%) was presented with the sucrose content divided by the content of molasses. The yield of isomaltulose using immobilized or free SIase $(\mathrm{g} / \mathrm{g})$ represents the isomaltulose content divided by the sucrose content in molasses. Sucrose conversion rate (\%) was described as the consumed sucrose for isomaltulose production divided by the total sucrose content in molasses. The dosage of SIase (U/g) was calculated with enzyme activity (U) divided by sucrose content (g). The dosage of $\alpha$-galactosidase (U/g) meant that enzyme activity $(\mathrm{U})$ was divided by SM content $(\mathrm{g})$.

\section{Statistical Analysis}

All tests were performed three times. The obtained data in experiments were analyzed through one-way ANOVA using SPSS 22.0 software (SPSS Inc., Chicago, MI, United States), and showed as mean \pm SD. $p$-values were calculated by Student's $t$-test $(n=3)$, and considered statistically significant when $P<0.05$.

\section{RESULTS AND DISCUSSION}

\section{Difference of Sugar Content in Three Kinds of Molasses}

Molasses as low-cost feedstock plays an important role in microbial production due to high sugar content (Zhan et al., 2020). The sucrose content is responsible for the performance to be the substrate for producing isomaltulose. The sucrose content $(51.2 \%)$ and dry matter $(78.3 \%)$ in $\mathrm{BM}$ were shown in Figure 1A, the sucrose proportion reached $97.2 \%$ in all the carbohydrates of $\mathrm{BM}$, which is the highest among the molasses, including $\alpha$-galactosidase treated SM. In addition to the major constituent sucrose, SM and CM had a higher content of other sugars. For instance, approximately $30 \%$ of monosaccharides 


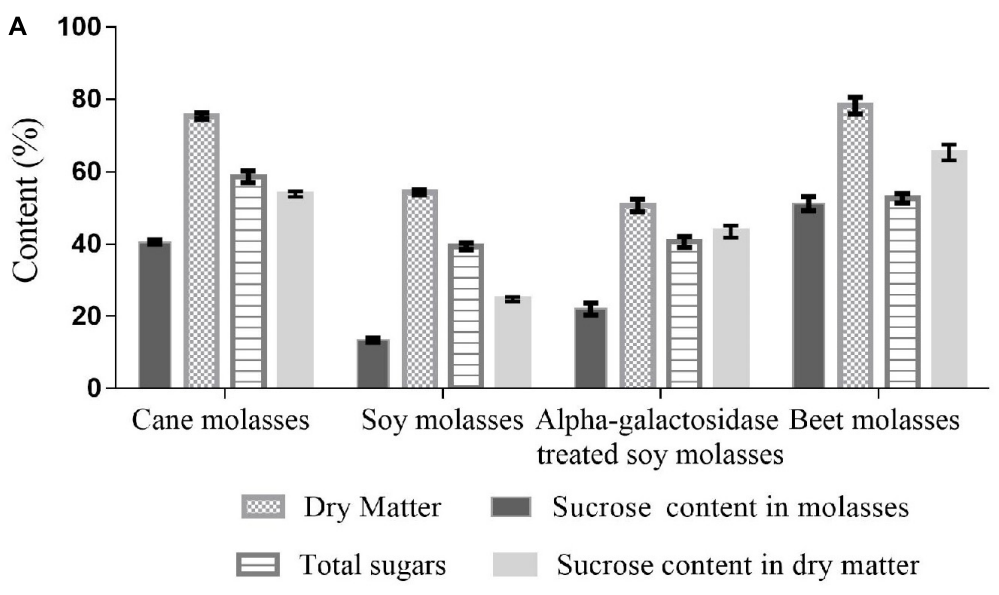

B

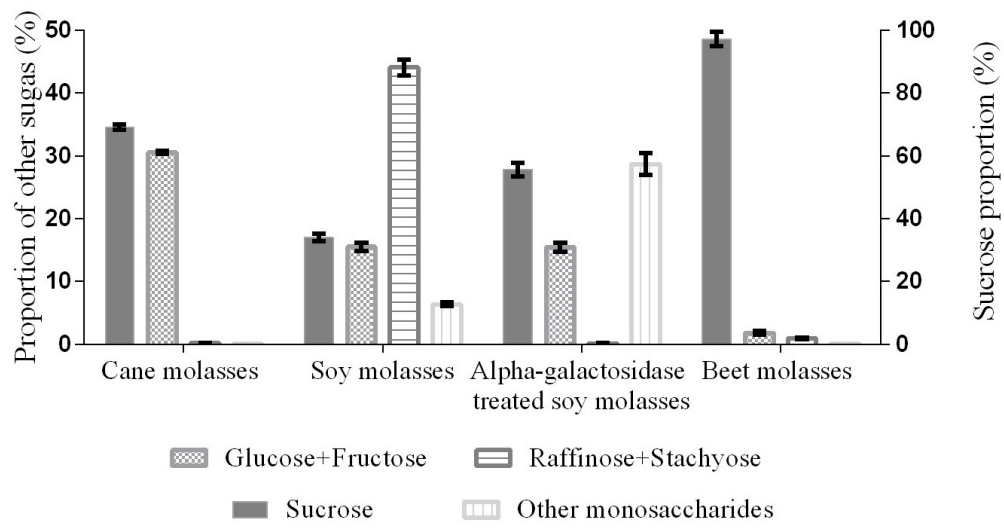

FIGURE 1 | Sugar content (A) and proportion (B) in different molasses.

(glucose and fructose) in CM and $44 \%$ of raffinose family oligosaccharides in SM were also exhibited (Figures 1A,B). This phenomenon possibly results from the differences in raw materials and processing technology of sugar manufacturing (Álvarez-Cao et al., 2019; Palmonari et al., 2020).

Feeding livestock with molasses is likely to bring metabolic diseases (urea toxicity, molasses toxicity, and bloat) (Senthilkumar et al., 2016). Microorganisms can use the sugars of molasses both as a carbon source and substrate through fermentation of food-grade strains to generate diverse high value-added products, such as bioethanol, $\alpha$-galactosidase, and isomaltulose (Álvarez-Cao et al., 2019; Roukas and Kotzekidou, 2020; Zhan et al., 2020). For example, CM (350 g/L) could be used to produce $161.2 \mathrm{~g} / \mathrm{L}$ isomaltulose by $Y$. lipolytica S47 strain (Wang et al., 2019a). By contrast, BM richer in sucrose than CM would show a higher capacity to serve as a suitable cost-effective substrate for isomaltulose production.

\section{Comparison of Isomaltulose Production Using Free and Immobilized Slase}

To avoid sucrose consumption and non-target products formation, specific enzyme catalysis application instead of free or immobilized microbial cells has been approved, which could improve substrate concentration and product purity (Zhang et al., 2019). As shown in Figure 2, the productions $(287.8 \pm 8.3 \mathrm{~g} / \mathrm{L})$ of isomaltulose synthesized by free SIase and immobilized SIase from sucrose were of the same highest values, and so did the yields $(0.96 \pm 0.03 \mathrm{~g} / \mathrm{g})$, among all the substrates. The results obtained keep the highest level from engineered $Y$. lipolytica strains using sucrose or CM to date (Zhang et al., 2018; Wang et al., 2019a).

Using immobilized SIase, the substrate pretreated BM achieved a higher isomaltulose production $(240.8 \mathrm{~g} / \mathrm{L})$ and a higher yield $(0.86 \mathrm{~g} / \mathrm{g})$ compared with free SIase, which were all significantly higher than those $(198.8 \mathrm{~g} / \mathrm{L}, 0.78 \mathrm{~g} / \mathrm{g})$ from raw BM using free or immobilized SIases (Figure 2). In contrast, the results obtained from raw BM decreased possibly due to the existence of metal ions restraining SIase activity. Most isomerases, including SIase, have been proved to be inhibited by metal ions, such as $\mathrm{Ca}^{2+}, \mathrm{Ba}^{2+}, \mathrm{Cu}^{2+}, \mathrm{Zn}^{2+}$, which are relatively rich in BM (Palmonari et al., 2020; Zhang et al., 2020). Pretreatment can reduce the content of those metal ions in BM, thus increasing the isomaltulose yield.

However, the production and yield of isomaltulose obtained from pretreated BM using immobilized SIase still hold distinctly 


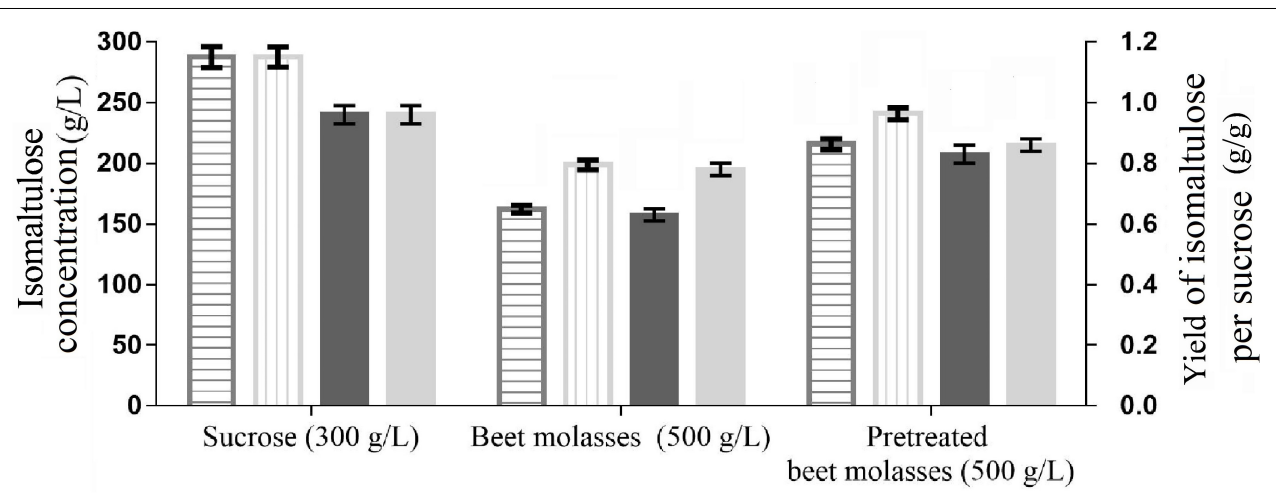

Isomaltulose concentration for free Slase $(\mathrm{g} / \mathrm{L})$

Isomaltulose concentration for immobilized SIase $(\mathrm{g} / \mathrm{L})$

Yield of isomaltulose per sucrose for immobilized SIase (g/g)

Yield of isomaltulose per sucrose for free SIase $(\mathrm{g} / \mathrm{g})$

FIGURE 2 | Isomaltulose production from different substrates by free and immobilized sucrose isomerase (Slase) under the conditions of Slase dosage of $15 \mathrm{U} / \mathrm{g}$, $\mathrm{pH}$ of 6 , and temperature of $40^{\circ} \mathrm{C}$.

higher levels than those catalyzed by different immobilized cells (such as Erwinia sp. D12, Klebsiella sp. K18, and S. plymuthica ATCC15928) (Mu et al., 2014) and many recombinant strains like Escherichia coli BL21(DE3) and Y. lipolytica (Li et al., 2017; Zheng et al., 2019; Zhang et al., 2020). The results confirmed that the pretreatment of BM is essential for efficient isomaltulose production. Simultaneously, immobilization of SIase benefits for production and yield of isomaltulose from pretreated BM.

\section{The Effect of Main Process Parameters on Isomaltulose Production by Immobilized Slase}

To further enhance the catalysis of immobilized SIase for isomaltulose synthesis, the catalysis conditions were examined. As exhibited in Figure 3A, isomaltulose was produced efficiently in a wide range of $\mathrm{pH}(5-7.5)$, especially ranging from 5 to 6 , and the $\mathrm{pH} 5.5$ was most suitable for isomaltulose synthesis, showing that the process is $\mathrm{pH}$-dependent and agrees with the activity of immobilized SIase (Zhang et al., 2019). In general, high substrate concentration facilitates catalysis using the immobilized enzyme. It was observed that the production of isomaltulose was continually rising as pretreated BM concentration increased, while the yield showed no significant changes before $800 \mathrm{~g} / \mathrm{L}$ pretreated BM but reduced remarkably beyond it (Figure 3B), achieving the best pretreated BM concentration of $800 \mathrm{~g} / \mathrm{L}$, containing $487.2 \mathrm{~g} / \mathrm{L}$ of sucrose. The high concentration of pretreated BM could be used for isomaltulose production due to the good tolerance of the immobilized SIase to high sucrose concentration (700 g/L) (Zhang et al., 2019), and the $\mathrm{H}_{2} \mathrm{SO}_{4}$ based pretreatment removing insoluble matters and reducing the viscosity of BM (Cheng et al., 2017); however, the concentration of $900 \mathrm{~g} / \mathrm{L}$ pretreated BM, equivalently with $668.7 \mathrm{~g} / \mathrm{L}$ whole dry matter, was not dissolved very well, indeed, which would be the main point responsible for lowering the yield of isomaltulose. This finding is higher than $350 \mathrm{~g} / \mathrm{L} \mathrm{CM}$ but is similar to the reported $800 \mathrm{~g} / \mathrm{L}$ SM used to produce isomaltulose (Wang et al., 2019a,b). Besides, the results in Figure 3C implied that $15 \mathrm{U} / \mathrm{g}$ of SIase was the best dosage from a series of dosages examined for isomaltulose production.

The reusability of immobilized SIase also needed to be evaluated in terms of industrial application. Under examined conversion conditions, the conversion rate of sucrose in pretreated BM remained at a high level exceeding $97.5 \%$ within the first eight cycles of repeated batches to produce isomaltulose (Figure 3D). Obviously, after which it decreased slightly from 9 to 11 cycles $(>94 \%)$ and decreased rapidly beyond 11 cycles (Figure 3D). To avoid disturbing crystal separation of isomaltulose by other sugars and obtain high-purity isomaltulose, the eighth batch was terminated when the conversion rate of sucrose was about $97.5 \%$. The finding was close to that ( $>90 \%$ ) by using sucrose substrate isomerized to isomaltulose using the targeted SIase for the first 13 batches (Zhang et al., 2019). Meanwhile, Wu et al. (2016) found that bacterial SIase immobilized onto $\varepsilon$-PL-gelatin remained about $80 \%$ conversion rate of sucrose from pure sucrose for the first $156 \mathrm{~h}$. The results stated that immobilized SIase has outstanding operational stability and good reusability using pretreated BM for industrial production of isomaltulose.

\section{Analysis of Sugar Composition in the Final Reaction Liquid for Isomaltulose Production}

Given the immobilized SIase of the eighth repeated batch still showed a high sucrose conversion rate $(97.5 \%)$, we conducted the 


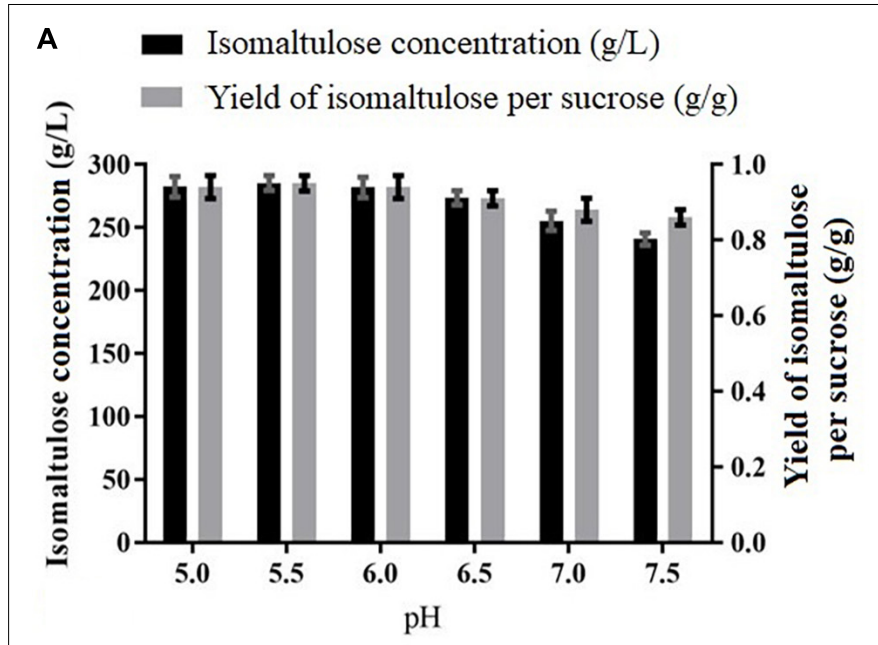

C

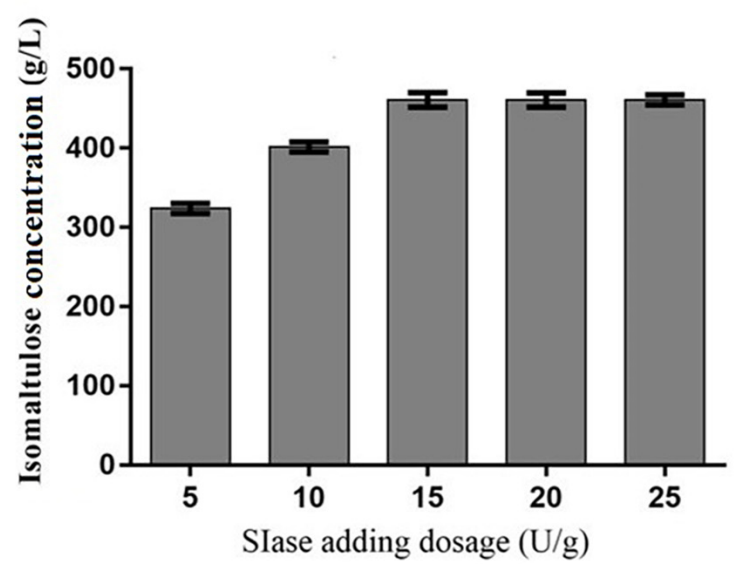

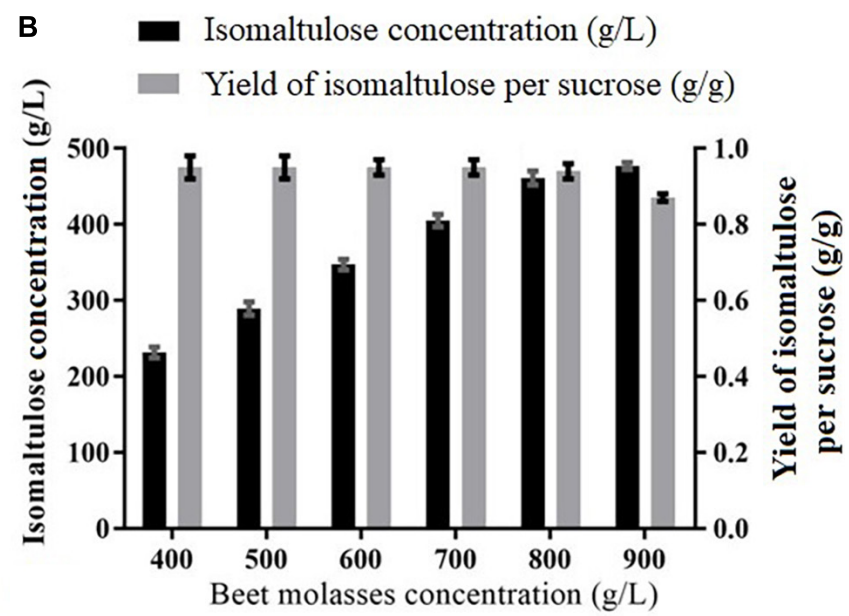

D

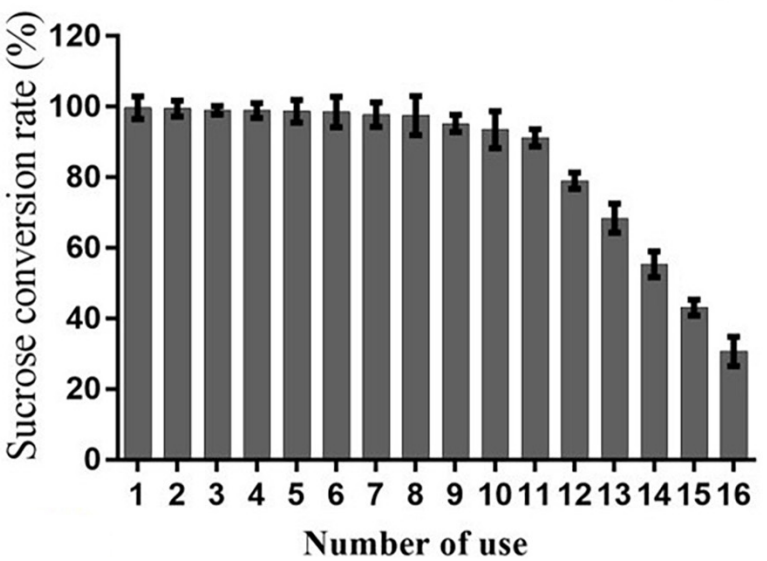

FIGURE 3 | Effects of different factors on isomaltulose production from pretreated beet molasses (BM) by immobilized Slase. (A) pH, (B) pretreated BM concentration, (C) Slase adding dosage, and (D) the effect of recycling number of immobilized Slase on sucrose conversion rate.

time course of the catalytic reaction. Under the best conditions (800 g/L pretreated $\mathrm{BM}, 40^{\circ} \mathrm{C}, 15 \mathrm{U}$ SIase/g, $\mathrm{pH} 5.5$ ) examined above, sucrose along with fast catalytic velocity was reduced to $12.18 \mathrm{~g} / \mathrm{L}$ at $10 \mathrm{~h}$ (Figure 4). Meanwhile, isomaltulose was increasingly accumulated to $446.4 \pm 5.5 \mathrm{~g} / \mathrm{L}$ with the yield of $0.94 \pm 0.02 \mathrm{~g} / \mathrm{g}$, yet small amounts of glucose and fructose $(37.51 \mathrm{~g} / \mathrm{L})$, and trehalulose $(24.1 \mathrm{~g} / \mathrm{L})$ were all slightly elevated due to hydrolysis and isomerization of SIase (Figures 4, 5). The isomaltulose production was improved dramatically than that of an initial condition (Figure 2), which is much higher than those (184.8 g/L, $209.4 \mathrm{~g} / \mathrm{L}, 212.6 \mathrm{~g} / \mathrm{L})$ produced by engineered Y. lipolytica strains and Bacillus subtilis from CM or SM (Wu et al., 2017; Wang et al., 2019b; Zheng et al., 2019). In contrast, the high yield $(0.94 \pm 0.02 \mathrm{~g} / \mathrm{g})$ observed is close to that $(0.96 \mathrm{~g} / \mathrm{g})$ produced from pure sucrose (Zhang et al., 2018, 2019). These results demonstrated that most of the sucrose in pretreated $\mathrm{BM}$ is converted to isomaltulose within $10 \mathrm{~h}$ in the eighth batch.

As shown by HPLC analysis in Figure 5, the purity of produced isomaltulose in the final reaction liquid was further identified to be $85.8 \%$, which is lower than (95.5\%) pure sucrose (Zhang et al., 2019), but distinctly overs the purity of isomaltulose (64\%) derived from SM by Y. lipolytica before using other strains to eliminate non-target sugars (Wang et al., 2019b). Interestingly, trehalulose only accounted for $4.6 \%$ of the total sugars, similar to the reported result (4\%) (Wu and Birch, 2004). It may be attributed to little flux of sucrose to trehalulose supported by SIase and heavy metals, such as $\mathrm{Ca}^{2+}, \mathrm{Ba}^{2+}, \mathrm{Cu}^{2+}, \mathrm{Zn}^{2+}$, in BM inhibiting SIase activity (Palmonari et al., 2020; Zhang et al., 2020). Furthermore, dried isomaltulose syrup (content $\geq 80 \%$ ), approved as GRAS (No. 681) in 2017 by FDA, can replace sucrose at the same level as sweeteners in foods and beverages (Tian et al., 2019).

Calculated with the conversion rate of the eighth batch, the total yield of isomaltulose per initial mass of pretreated $\mathrm{BM}$ was $0.558 \mathrm{~g} / \mathrm{g}$, while the total yield of isomaltulose per pure sucrose was $0.96 \mathrm{~g} / \mathrm{g}$. Considering the low cost of $\mathrm{BM}$, the yield was desirable. In addition, by repeated enzymatic conversion, immobilized SIase $(1 \mathrm{U})$ could catalyze the synthesis of $0.51 \mathrm{~g}$ of isomaltulose. Using fermented SIase 


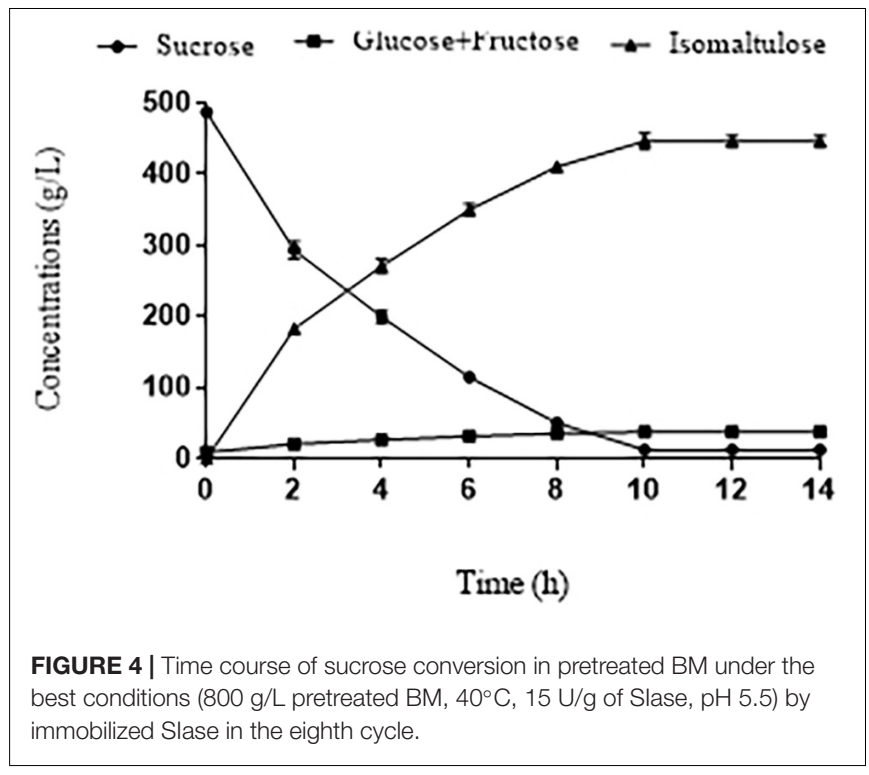

with an activity of $49.3 \mathrm{U} / \mathrm{mL}$, SIase of $1 \mathrm{ml}$ taken from the fermentation broth could catalyze the synthesis of $25 \mathrm{~g}$ of isomaltulose. Pretreatment can reduce the content of those metal ions in BM, thus increasing the isomaltulose yield and the immobilization of enzyme notably reduced the enzyme demand. These results indicated that the bioprocess using pretreated BM and immobilized SIase is a feasible alternative approach for isomaltulose production.

\section{Comparison of the Cost for Isomaltulose Production}

The cost of sucrose accounts for a substantial part of the total cost of producing isomaltulose based on the sole substitute sucrose
TABLE 1 | Comparison of the costs from different substrates for isomaltulose production by different engineered food-grade strains and the purity of isomaltulose.

\begin{tabular}{|c|c|c|c|c|}
\hline Strains & $\begin{array}{c}\text { Substrate } \\
\text { cost } \\
\text { (yuan/ton } \\
\text { isomaltulose) }\end{array}$ & $\begin{array}{l}\text { Isomaltulose } \\
\text { production } \\
\text { (g/L) }\end{array}$ & $\begin{array}{c}\text { Isomaltulose } \\
\text { proportion } \\
(\%)\end{array}$ & References \\
\hline $\begin{array}{l}\text { Lactococcus } \\
\text { lactis }\end{array}$ & Sucrose, 9000 & 36 & $<90$ & $\begin{array}{l}\text { Park et al., } \\
2010\end{array}$ \\
\hline $\begin{array}{l}\text { Saccharomyces } \\
\text { cerevisiae }\end{array}$ & Sucrose, 9000 & $<4$ & $<10$ & Lee et al., 2011 \\
\hline Y. lipolytica & Sucrose, 8300 & 572.1 & 97.8 & $\begin{array}{l}\text { Zhang et al., } \\
2018\end{array}$ \\
\hline Bacillus subtilis & CM, 3800 & 212.6 & $<92.4$ & Wu et al., 2017 \\
\hline Y. lipolytica & CM, 3600 & 161.2 & 97.4 & $\begin{array}{l}\text { Wang et al., } \\
2019 a\end{array}$ \\
\hline Y. lipolytica & SM, 3800 & 209.4 & 97.8 & $\begin{array}{l}\text { Wang et al., } \\
2019 \mathrm{~b}\end{array}$ \\
\hline Y. lipolytica & BM, 2700 & 446.4 & 85.8 & This study \\
\hline
\end{tabular}

or for microbial conversion needing sucrose and other nutrients (Zhang et al., 2019, 2020). The estimation of alternative feedstock cost is indispensable for sustainable industrial production of isomaltulose. The costs of feedstocks were based on the current market prices. As shown in Table 1, high substrate costs for isomaltulose production were evaluated by engineered strains cultivated from sucrose-containing substrates; however, the cost of single BM in this study was observed at 2700 yuan (RMB) per ton isomaltulose based on the whole yield (isomaltulose obtained from the substrate) (Table 1). This reduces the feedstock costs by $25-28.9 \%$ and by more than $70 \%$, compared with the cost of other molasses and sucrose as the substrate (Table 1), respectively. More important, the immobilized SIase with high reusability could remarkably reduce the enzyme demand and production cost. The cost of the enzyme can

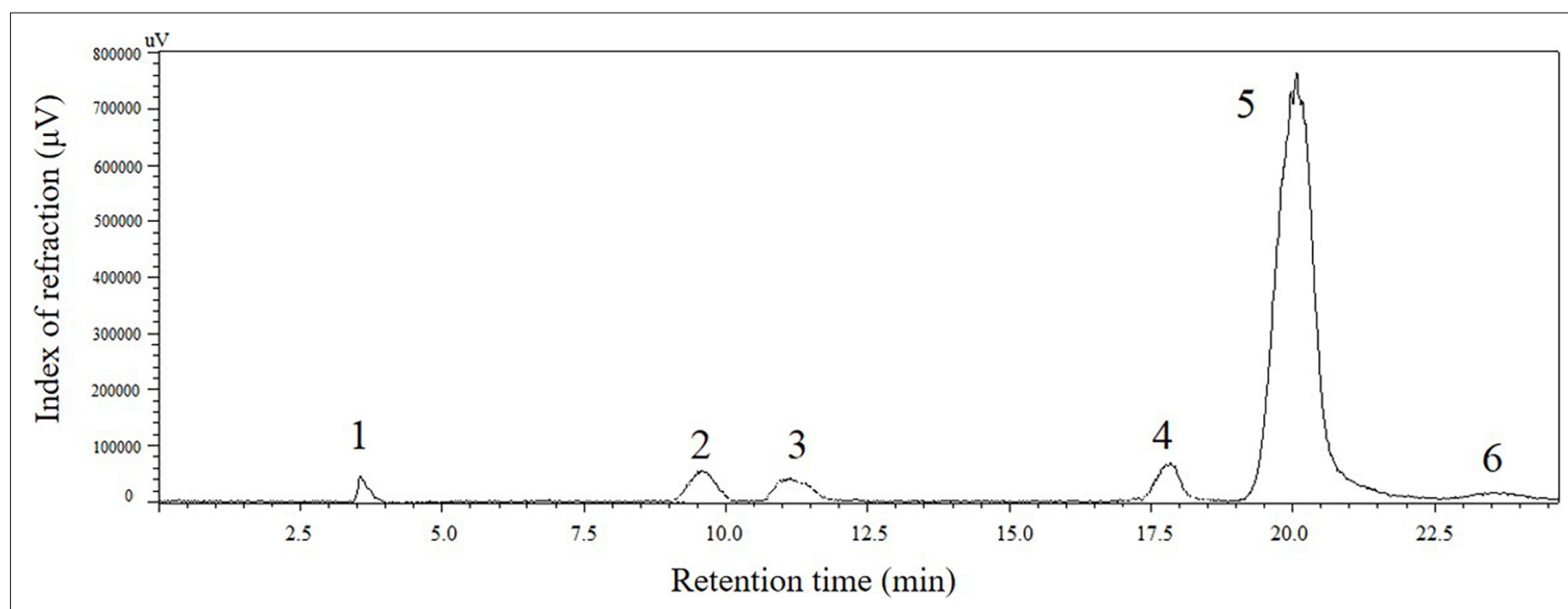

FIGURE 5 | High-performance liquid chromatography (HPLC) profile of products in catalytic liquid of pretreated BM using immobilized Slase in the eighth cycle at $10 \mathrm{~h}$. The numbers from 1 to 6 represent solvent, glucose, fructose, sucrose, isomaltulose, and trehalulose, respectively. 
be negligible, in general. Economic analysis revealed that significant cost reduction of isomaltulose production from lowcost BM in this study is reliable for industrial application.

\section{CONCLUSION}

A two-step process for isomaltulose production from costeffective BM instead of sucrose was introduced. The $\mathrm{H}_{2} \mathrm{SO}_{4}$ pretreated $\mathrm{BM}$ confirmed a more efficient substrate to synthesize isomaltulose than untreated BM, and the immobilized SIase using pretreated $\mathrm{BM}$ as a substrate was verified to be the best for isomaltulose production. This process could produce a high concentration level of isomaltulose of $446.4 \pm 5.5 \mathrm{~g} / \mathrm{L}$ with a yield of $0.94 \mathrm{~g} / \mathrm{g}$ and a purity of $85.8 \%$ under the best conditions in the eighth batch, and also remain $97.5 \%$ of the sucrose conversion rate. Immobilized SIase used in repeated batch reaction showed good reusability to convert pretreated BM into isomaltulose. It is also economically feasible as shown by economic analysis. This study provides an economical, effective, and promising approach for potential industrial isomaltulose production.

\section{REFERENCES}

Álvarez-Cao, M. E., Cerdán, M. E., González-Siso, M. I., and Becerra, M. (2019). Bioconversion of beet molasses to alpha-galactosidase and ethanol. Front. Microbiol. 10:405. doi: 10.3389/fmicb.2019.00405

Cheng, C., Zhou, Y., Lin, M., Wei, P., and Yang, S. T. (2017). Polymalic acid fermentation by Aureobasidium pullulans for malic acid production from soybean hull and soy molasses: fermentation kinetics and economic analysis. Bioresour. Technol. 223, 166-174. doi: 10.1016/j.biortech.2016.10.042

de Oliva-Neto, P., and Menão, P. T. P. (2009). Isomaltulose production from sucrose by Protaminobacter rubrum immobilized in calcium alginate. Bioresour. Technol. 100, 4252-4256. doi: 10.1016/j.biortech.2009.03.060

Du, Q., Fu, M., Zhou, Y., Cao, Y. P., Guo, T. W., Zhou, Z., et al. (2020). Sucrose promotes caries progression by disrupting the microecological balance in oral biofilms: an in vitro study. Sci. Rep. 10, 1-12.

Duan, X., Cheng, S., Ai, Y. X., and Wu, J. (2016). Enhancing the thermostability of Serratia plymuthica sucrose isomerase using B-factor-directed mutagenesis. PLoS One 11:e0149208. doi: 10.1371/journal.pone.0149208

Emrah, S., Siamak, A., Kamal, E., Harun, K., Ufuk, G., Inci, E., et al. (2018). Biological hydrogen production from sugar beet molasses by agar immobilized R. capsulatus in a panel photobioreactor. Int. J. Hydrogen Energ. 43, 1498714995. doi: 10.1016/j.ijhydene.2018.06.052

Ferrari, M. D., Bianco, R., Froche, C., and Loperena, M. L. (2001). Baker's yeast production from molasses/cheese whey mixtures. Biotechnol. Lett. 23, 1-4.

Gao, X., Yang, Y., and Deng, H. (2011). Utilization of beet molasses as a grinding aid in blended cements. Constr. Build. Mater. 25, 3782-3789. doi: 10.1016/j. conbuildmat.2011.04.041

Germe, M., and Turhan, I. (2020). Thermostability of Aspergillus niger inulinase from sugar-beet molasses in the submerged fermentation and determination of its kinetic and thermodynamic parameters. Biomass Convers. Bior. doi: 10.1007/ s13399-020-00809-8

Lee, E. J., Moon, Y., and Kweon, M. (2020). Processing suitability of healthful carbohydrates for potential sucrose replacement to produce muffins with staling retardation. LWT 131:109565. doi: 10.1016/j.lwt.2020.109565

Lee, G. Y., Jung, J. H., Seo, D. H., Hansin, J., Ha, S. J., Cha, J., et al. (2011). Isomaltulose production via yeast surface display of sucrose isomerase from Enterobacter sp. FMB-1 on Saccharomyces cerevisiae. Bioresour. Technol. 102, 9179-9184. doi: 10.1016/j.biortech.2011.06.081

Li, L. J., Wang, H. W., Cheng, H. R., and Deng, Z. X. (2017). Isomaltulose production by yeast surface display of sucrose isomerase from Pantoea dispersa

\section{DATA AVAILABILITY STATEMENT}

The original contributions presented in the study are included in the article/supplementary material, further inquiries can be directed to the corresponding authors.

\section{AUTHOR CONTRIBUTIONS}

Q-QW performed the experiment and wrote the manuscript. $\mathrm{J}-\mathrm{HH}$ implemented fermentation and revised the manuscript. $\mathrm{Z}-\mathrm{CM}$ designed the experiment and published the manuscript. All authors contributed to the article and approved the submitted version.

\section{FUNDING}

This research was funded by the Central Public-interest Scientific Institution Basal Research Fund, CAFS (No. 2020TD67) and Shandong Provincial Natural Science Foundation (ZR2016BQ42).

on Yarrowia lipolytica. J. Func. Foods 32, 208-217. doi: 10.1016/j.jff.2017. 02.036

Li, S., Cai, H., Qing, Y. J., Ren, B., Xu, H., Zhu, H. Y., et al. (2011). Cloning and characterization of a sucrose isomerase from Erwinia rhapontici NX-5 for isomaltulose hyperproduction. Appl. Biochem. Biotech. 163, 52-63. doi: 10.1007/s12010-010-9015-Z

Li, S., Xu, H., Yu, J., Wang, Y., Feng, X., and Ouyang, P. (2013). Enhancing isomaltulose production by recombinant Escherichia coli producing sucrose isomerase: culture medium optimization containing agricultural wastes and cell immobilization. Bioproc. Biosyst. Eng. 36, 1395-1405. doi: 10.1007/s00449-0120877-z

Li, X., Zhao, C., An, Q., and Zhang, D. (2003). Substrate induction of isomaltulose synthase in a newly isolated Klebsiella sp. LX3. J. Appl. Microbiol. 95, 521-527. doi: 10.1046/j.1365-2672.2003.02006.x

Lightowler, H., Schweitzer, L., Theis, S., and Henry, C. J. (2019). Changes in weight and substrate oxidation in overweight adults following isomaltulose intake during a 12-week weight loss intervention: a randomized, double-blind, controlled trial. Nutrients 11:2367. doi: 10.3390/nu11102367

Liu, L., Bilal, M., Luo, H. Z., Zhao, Y. P., and Duan, X. G. (2020). Studies on biological production of isomaltulose using sucrose isomerase: current status and future perspectives. Catal. Lett. 151, 1868-1881. doi: 10.1007/s10562-02003439-x

Mu, W., Li, W., Wang, X., Zhang, T., and Jiang, B. (2014). Current studies on sucrose isomerase and biological isomaltulose production using sucrose isomerase. Appl. Microbiol. Biot. 98, 6569-6582. doi: 10.1007/s00253-0145816-2

Ozdal, M., and Başaran Kurbanoglu, E. (2019). Use of chicken feather peptone and sugar beet molasses as low cost substrates for xanthan production by Xanthomonas campestris MO-03. Fermentation 5:9. doi: 10.3390/ fermentation5010009

Palmonari, A., Cavallini, D., Sniffen, C. J., Fernandes, L., Holder, P., Fagioli, L., et al. (2020). Short communication: characterization of molasses chemical composition. J. Dairy Sci. 103, 6244-6249. doi: 10.3168/jds.2019-17644

Park, J. Y., Jung, J. H., Seo, D. H., Ha, S. J., Yoon, J. W., Kim, Y. C., et al. (2010). Microbial production of palatinose through extracellular expression of a sucrose isomerase from Enterobacter sp. FMB-1 in Lactococcus lactis MG1363. Bioresour. Technol. 101, 8828-8833. doi: 10.1016/j.biortech.2010.06.068

Razmovski, R., and Vučurović, V. (2012). Bioethanol production from sugar beet molasses and thick juice using Saccharomyces cerevisiae immobilized on maize stem ground tissue. Fuel 92, 1-8. doi: 10.1016/j.fuel.2011.07.046 
Roukas, T., and Kotzekidou, P. (2020). Rotary biofilm reactor: a new tool for long-term bioethanol production from non-sterilized beet molasses by Saccharomyces cerevisiae in repeated-batch fermentation. J. Clean. Prod. 257:120519. doi: 10.1016/j.jclepro.2020.120519

Senthilkumar, S., Suganya, T., Deepa, K., Muralidharan, J., and Sasikala, K. (2016). Supplementation of molasses in livestock feed. Int. J. Sci. Environ. Technol. 5, 1243-1250.

Shyam, S., Ramadas, A., and Chang, S. K. (2018). Isomaltulose: recent evidence for health benefits. J. Funct. Foods 48, 173-178. doi: 10.1016/j.jff.2018. 07.002

Taskin, M., Ortucu, S., Aydogan, M. N., and Arslan, N. P. (2016). Lipid production from sugar beet molasses under non-aseptic culture conditions using the oleaginous yeast Rhodotorula glutinis TR29. Renewable Energy 99, 198-204. doi: 10.1016/j.renene.2016.06.060

Tian, Y. Q., Deng, Y., and Zhang, W. M. (2019). Sucrose isomers as alternative sweeteners: properties, production, and applications. Appl. Microbiol. Biot. 103, 8677-8687.

Vučurović, V. M., Puskas, V. S., and Miljic, U. D. (2019). Bioethanol production from sugar beet molasses and thick juice by free and immobilised Saccharomyces cerevisiae. J. I. Brewing 125, 134-142. doi: 10.1002/jib.536

Wang, Z. P., Wang, Q. Q., Liu, S., Liu, X. F., Yu, X. J., and Jiang, Y. L. (2019a). Efficient conversion of cane molasses towards high-purity isomaltulose and cellular lipid using an engineered Yarrowia lipolytica strain in fed-batch fermentation. Molecules 24:1228. doi: 10.3390/molecules 24071228

Wang, Z. P., Zhang, L. L., Liu, S., Liu, X. Y., Liu, X. Y., and Yu, X. J. (2019b). Whole conversion of soybean molasses into isomaltulose and ethanol by combining enzymatic hydrolysis and successive selective fermentations. Biomolecules 9:353. doi: 10.3390/biom9080353

Wu, L., and Birch, R. G. (2004). Characterization of Pantoea dispersa UQ68J: producer of a highly efficient sucrose isomerase for isomaltulose biosynthesis. J. Appl. Microbiol. 97, 93-103. doi: 10.1111/j.1365-2672.2004.02274.x

Wu, L., Qiu, J., Wu, S., Liu, X., Liu, C., Xu, Z., et al. (2016). Bioinspired production of antibacterial sucrose isomerase-sponge for the synthesis of isomaltulose. $A d v$. Synth. Catal. 358, 4030-4040. doi: 10.1002/adsc.201600705

Wu, L. T., Wu, S. S., Qiu, J. J., Xu, C. X., Li, S., and Xu, H. (2017). Green synthesis of isomaltulose from cane molasses by Bacillus subtilis WB800-pHA01-palI in a biologic membrane reactor. Food Chem. 229, 761-768. doi: 10.1016/j. foodchem.2017.03.001
Yan, D., Lu, Y., Chen, Y. F., and Wu, Q. (2011). Waste molasses alone displaces glucose-based medium for microalgal fermentation towards costsaving biodiesel production. Bioresour. Technol. 102, 6487-6493. doi: 10.1016/ j.biortech.2011.03.036

Yeh, S. H. H., Shie, F. S., Liu, H. K., Yao, H. H., Kao, P. C., Lee, Y. H., et al. (2020). A high-sucrose diet aggravates Alzheimer's disease pathology, attenuates hypothalamic leptin signaling, and impairs food-anticipatory activity in APPswe/PS1dE9 mice. Neurobiol. Aging 90, 60-74. doi: 10.1016/j. neurobiolaging.2019.11.018

Zhan, Y. J., Zhu, P., Liang, J. F., Xu, Z., Feng, X. H., Liu, Y., et al. (2020). Economical production of isomaltulose from agricultural residues in a system with sucrose isomerase displayed on Bacillus subtilis spores. Bioproc. Biosyst. Eng. 43, 75-84. doi: 10.1007/s00449-019-02206-6

Zhang, F., Cheng, F., Jia, D. X., Gu, Y. H., Liu, Z. Q., and Zheng, Y. G. (2020). Characterization of a recombinant sucrose isomerase and its application to enzymatic production of isomaltulose. Biotechnol. Lett. 43, 261-269. doi: 10. 1007/s10529-020-02999-7

Zhang, P., Wang, Z. P., Liu, S., Wang, Y. L., Zhang, Z. F., Liu, X. M., et al. (2019). Overexpression of secreted sucrose isomerase in Yarrowia lipolytica and its application in isomaltulose production after immobilization. Int. J. Biol. Macromol. 121, 97-103. doi: 10.1016/j.ijbiomac.2018.10.010

Zhang, P., Wang, Z. P., Sheng, J., Zheng, Y., Ji, X. F., Zhou, H. X., et al. (2018). High and efficient isomaltulose production using an engineered Yarrowia lipolytica strain. Bioresource Technol. 265, 577-580. doi: 10.1016/j.biortech.2018.06.081

Zheng, Y., Wang, Z. P., Ji, X. F., and Sheng, J. (2019). Display of a sucrose isomerase on the cell surface of Yarrowia lipolytica for synthesis of isomaltulose from sugar cane by-products. 3 Biotech 9:179.

Conflict of Interest: The authors declare that the research was conducted in the absence of any commercial or financial relationships that could be construed as a potential conflict of interest.

Copyright (c) 2021 Wang, Yang, Hao and Ma. This is an open-access article distributed under the terms of the Creative Commons Attribution License (CC BY). The use, distribution or reproduction in other forums is permitted, provided the original author(s) and the copyright owner(s) are credited and that the original publication in this journal is cited, in accordance with accepted academic practice. No use, distribution or reproduction is permitted which does not comply with these terms. 